certain long term motor consequences of its treatment.

JOHN L WADDINGTON

Department of Clinical Pharmacology,

Royal College of Surgeons in Ireland,

Dublin 2

HaNafy A Youssef

St Davnet's Hospital,

Monaghan

1 Waddington JL. Tardive dyskinesia in schizophrenia and other disorders: associations with ageing, cognitive dysfunction and structural brain pathology in relation to neuroleptic exposure. Human Psychopharmacology 1987;2:11-22.

2 Youssef HA, Waddington JL. Primitive (developmental) reflexes and diffuse cerebral dysfunction in schizophrenia and bipolar affective disorder: over representation in patients with tardive dyskinesia. Biol Psychiatry (in press).

3 Paulson G, Gottleib G. Developmental reflexes: the reappearance of foetal and neonatal reflexes in aged patients. Brain 1968;91: $37-52$.

4 Waddington JL, Youssef HA, Dolphin C, Kinsella A. Cognitive dysfunction, negative symptoms and tardive dyskinesia in dysfunction, negative symptoms and tardive dyskinesia in
schizophrenia: their association in relation to topography of schizophrenia: their association in relation to topography of
involuntary movements and criterion of their abnormality. involuntary movements and cric

5 Amato $M$, Howald $H$, von Muralt $G$. Fetal sex distribution of peri-intraventricular hemorrhage in preterm infants. Eur Neurol 1987;27:20-3.

\section{Reported management of threatened miscarriage by general practitioners in Wessex}

SIR,-We were dismayed to read in the report by Dr Christopher Everett and colleagues (5 September, $p$ 583) that among general practitioners in Wessex $29 \%$ never gave anti-D to $R h(D)$ negative women after a complete abortion, and $77 \%$ never gave it for threatened abortion.

Though few fetal cell's reach the mother's circulation during abortion, it has long been recognised that these may be enough to sensitise some of the $15 \%$ of women who are $R h(D)$ negative. ${ }^{1} A$ minority of these women are not only able to respond to a tiny inoculum of $R h(D)$ positive cells but often generate the highest antibody levels, and subsequently suffer the worst problems from haemolytic disease of the newborn. The recommended policy is therefore to give prophylactic $R h(D)$ immunoglobulin to all $R h(D)$ negative aborting mothers, including, when necessary, even those who do not need it rather than missing those who do. When the $R h(D)$ state of mothers (especially primiparas) is unknown and cannot practicably be determined within 72 hours many people give prophylaxis anyway. It is thus essential that general practices carry a small stock of $R h(D)$ immunoglobulin to cater for such circumstances, in accordance with published advice. ${ }^{2}$

The incidence of haemolytic disease of the newborn fell dramatically after the introduction of prophylaxis but has levelled off at around $2 \cdot 6$ cases per 1000 live births, with a persistent fetal loss rate of about 0.1 per 1000 live births. Failures of administration of immunoglobulin account for many new sensitisations, and the survey referred to above points to a substantial source of those failures. Clear cut authoritative guidelines were published by the Department of Health and Social Security in 1971, revised in 1981, and distributed to all family practitioner committees. Summarised briefly, these require that all $R h(D)$ negative women receive an appropriate dose of anti-D immunoglobulin (500 IU (100 $\mu \mathrm{g})$ for deliveries after 20 weeks and $250 \mathrm{IU}(50 \mu \mathrm{g})$ for deliveries before 20 weeks and sensitising episodes).

The dose should be given within 72 hours of delivery (unless the baby is known to be $R h(D)$ negative), after abortion at whatever stage of pregnancy, and after every sensitising episode during pregnancy. These include threatened abortion, antepartum haemorrhage, version, amniocentesis, and abdominal injuries.

The guidelines also recommended that the Kleihaur test to estimate the size of the fetal bleed is used wherever possible and that larger doses of anti- $\mathrm{D}$ immunoglobulin should be administered if the size of the fetal bleed merits it. If the published recommended guidelines are overlooked, as the recent survey suggests, we cannot expect any further reduction in the incidence of haemolytic disease of the newborn.

C C ENTWISTLE

Regional Blood Transfusion Centre,

P J BOWELI

Oxford,

L A D TOVEY

Regional Blood Transfusion Centre,

Leeds

1 Queenan JT. Role of Rh o (D) immune globulin in induced abortions. Clin Obstet Gynecol 1970;14:235-44.

2 Department of Health and Social Security, Scottish Home and Health Department, Welsh Office. Haemolytic disease of the newborn. London: HMSO, 1976. (Addendum, 1981.)

SIR,-Dr Christopher Everett and colleagues advocate the use of portable ultrasound machines by general practitioners to help in the management of miscarriages (5 September, p 583). We agree that the quickest and most accurate means of assessing a threatened miscarriage is to perform an urgent ultrasound examination. We believe, however, that the provision of a portable ultrasound scanner to all general practitioner partnerships is not a practical proposition because of the capital cost and the difficulty of training sufficient doctors to run a safe service. A further problem would be the time that the practitioners would have to spend on domiciliary visits while waiting for the patients bladders to fill.

We run a service whereby the local practitioners refer all cases of threatened or partial miscarriage directly to our radiology department. The patients are instructed to drink at least a pint of water before leaving their home (or doctor's surgery), are sent directly to the ultrasound room on arrival at the hospital, and are examined in between those with appointments. If the pregnancy is viable or the miscarriage is complete and the haemorrhage ceasing they are referred back to their genera practitioners. If the miscarriage is incomplete or heavy bleeding persists they are referred to the on call gynaecology team for further assessment.

This system has the advantages of speed and simplicity. The patients are examined by a consultant radiologist with a good quality scanner without delay and without the need for a forma appointment (a covering letter or phone cal is all that we ask). The system relies on close liaison between the departments of radiology and gynaecology and, in particular, on the flexibility of the radiographers in fitting in extra scans with minimal notice. In practice, we have found that the staff find this a rewarding and worthwhile service. A clinical trial of the efficacy and safety of this method of management has been completed and will shortly be submitted for publication.

\section{P G P STODDART} M HoulTON

General Hospital,

Weston super Mare,

Avon BS23 4TQ

\section{Chronic prostatitis}

SIR,-I agree in sentiment with Dr Rosalind Maskell's views on prostatitis (5 September, $p$ 611 ), in that the harder you look the more likely you are to find an underlying infective aetiology.
The problem, however, with Dr Maskell's work on fastidious organisms and their presence in 3 the urine of symptomatic patients is that it is 0 uncontrolled. To validate her statements on the role of fastidious organisms in prostatitis would $\widehat{\Omega}$ require a controlled study with isolation data $\overline{\bar{F}}$ on asymptomatic patients, proper follow up of treated patients, and a placebo group. Fastidious $\Phi$ organisms may have every right to be present in the urethra of some patients and hence may be present $\varrho$ in the voided urine. I note that in Dr Maskell'srecent paper only $33 \%$ of the patients in whom such organisms were cultured had pyuria, as, $\overline{0}$ incidentally, did $12 \%$ of those with bacteriologically sterile urine. ${ }^{1}$

Much further research into prostatitis is needed, $\frac{0}{\vec{D}}$ particularly into so called abacterial prostatitis, $\varrho$ before the possible role of fastidious organisms $\&$ may be validated. Dr Maskell's views of the role of fastidious organisms are acknowledged by her own ${ }^{\circ}$ peers as controversial ${ }^{2}$ and until more convincing $\vec{C}$ data are forthcoming must continue to be con- $\mathrm{O}$ sidered so. Hamilton-Miller et al concluded that음 "management as opposed to mere treatment, demands as much attention to the clinical history as to the clinical examination and microbiologicalor investigations of the most appropriate specimens."요 This view I heartily endorse; frequency and dysuria syndrome, whether in men or women, with a psychological basis has specific clinical features, which allow it to be distinguished from true $\frac{1}{0}$ infection.

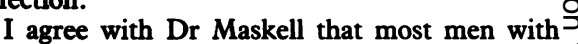
a diffuse perineal and genitourinary symptom $\vec{V}$ complex usually consult their general practitioners $\bigcirc$ for advice first. It was to them that my answer to the question on abacterial prostatitis was directed. I believe that positive evidence of prostatitis should $\stackrel{\mathbb{}}{-}$ be sought before the patient is labelled as having $\overrightarrow{\mathscr{C}}$ the condition, as management becomes extremely $\infty$ difficult once the patient believes that he has ${ }^{-}$ prostatitis. These, of course, are the very patients that are then referred to urologists. They have usually had treatment with various antibiotics for a variable length of time with absolutely no improvement in their symptom complex. Life $\frac{\mathbb{Q}}{2}$ would be easy if most of these men had even a fairly obscure infective aetiology to account for theirō symptoms, as appropriate treatment would then be 3 simple. Unfortunately, this is almost invariably not the case, and the term "prostatodynia" has? arisen to describe this large group of patients with symptoms suggesting prostatitis but in whom no evidence of an infective cause is detected.

Department of Urology

Southmead General Hospital

Bristol BS10 5NB

J C GINGELL

1 Clarke M, Pead L, Maskell R. Urinary infection in adult men: laboratory perspective. $\mathrm{Br} \mathcal{Z}$ Unol 1985;57:222-6.

2 Hamilton-Miller JMT, Brumfitt W, Smith GW. Are fastidious organisms an important cause of dysuria and frequency? TheO case against. In: Asscher AW, Brumfitt W, eds. Microbial disease in nephrology. London: John Wiley and Sons, 1986.

Should medical students go to South Africa?

SIR,-Perhaps a financial adviser should address himself to materia non medica, but as the son and ${ }^{\text {- }}$ brother of South African doctors and the fiancé of $a$ British house officer, I feel able to venture an opinion on Ms Helen Gray's article about her尺 South African elective (5 September, p 398) and $\mathbb{\Phi}$ Mr Tom Coffey's response (26 September, p 781). Miss Gray should note that in visiting the Cape she was surrounded by South Africa's most liberalô whites and among its least poverty stricken blacks.? Her impressions must then be qualified by the knowledge that in the more rural areas of South 